\title{
Development of a Flow Injection System for Differential Pulse Amperometry and Its Application for Diazepam Determination
}

\author{
Vesna Antunović, ${ }^{1}$ Slavna Tešanović, ${ }^{2}$ Danica Perušković, ${ }^{2}$ Nikola Stevanović, ${ }^{2}$ \\ Rada Baošić, ${ }^{2}$ Snežana Mandić, ${ }^{2}$ and Aleksandar Lolićc $\mathbb{D}^{2}$ \\ ${ }^{1}$ Faculty of Medicine, University of Banja Luka, 78000 Banja Luka, Bosnia and Herzegovina \\ ${ }^{2}$ Faculty of Chemistry, University of Belgrade, 11000 Belgrade, Serbia \\ Correspondence should be addressed to Aleksandar Lolić; lolix@chem.bg.ac.rs
}

Received 29 September 2017; Accepted 8 February 2018; Published 19 March 2018

Academic Editor: Josep Esteve-Romero

Copyright (c) 2018 Vesna Antunović et al. This is an open access article distributed under the Creative Commons Attribution License, which permits unrestricted use, distribution, and reproduction in any medium, provided the original work is properly cited.

\begin{abstract}
This work presents the development of a flow injection system for differential pulse amperometry (DPA) for diazepam determination in the presence of oxygen. The thin flow cell consisted of the bare glassy carbon electrode, reference silver/silver chloride, and stainless steel as the auxiliary electrode. Electrochemical reduction of diazepam (DZP) was characterised by cyclic voltammetry. Azomethine reduction peak was used for DZP quantification. The detector response was linear in the range $20-250 \mu \mathrm{mol} / \mathrm{dm}^{3}$ of diazepam, with a calculated detection limit of $3.83 \mu \mathrm{g} / \mathrm{cm}^{3}$. Intraday and interday precision were 1.53 and $10.8 \%$, respectively. The method was applied on three beverage samples, energetic drink, and two different beer samples, and obtained recoveries were from 93.65 up to $104.96 \%$. The throughoutput of the method was up to 90 analyses per hour.
\end{abstract}

\section{Introduction}

Amperometric detection can operate in three different modes: constant potential, pulse mode, and differential pulse (or multi pulse mode). Detection at constant potential is usually applied with flow injection analysis systems because simple and cheap potentiostats can be used. When an analyte passes through the detector, it generates a current proportional to the analyte concentration [1].

Differential pulse amperometry (DPA) is a technique described and first applied by Marcenac and Gonon in 1985 [2]. In DPA, a clean potential is applied for electrode cleaning without current sampling. Then two potential pulses are applied after the cleaning step, and the current at the end of each pulse is recorded as the function of time. During the experiment, only the difference of two current samples is displayed. Obtained dependence of $\Delta I$ (the difference of the currents recorded at the end of each potential pulse) with time is named differential pulse amperogram [3]. The main advantage of DPA is that its signal is less affected by interferences than with the other amperometric modes.
Throughout the years, DPA has been used for determination of various substances in a flow injection (FI) system. Quadrupole-pulsed amperometric detection was applied for simultaneous determination of glucose and fructose in a FI system [4]. The first pulse was used for the oxidation of glucose and the second for both analytes. The subtraction of obtained currents was used for quantification of fructose. Three-pulse FI-DPA was used for simultaneous determination of phenolic antioxidants (butylated hydroxyanisole and butylated hydroxytoluene) at a boron-doped diamond electrode [5]. Multiple-pulse amperometric flow injection system was described for simultaneous determination of pharmaceutical active substances, paracetamol and ascorbic acid [6], caffeine, ibuprofen, and paracetamol [7], and dypirone and paracetamol in pharmaceutical formulations on a bare glassy carbon electrode (GCE) [8]. A simple, fast and low-cost multiple-pulse amperometric FI system was applied for determination of sildenafil citrate (SC) in Viagra [9]. Three sequential potential pulses were applied as a function of time. SC is detected at two different irreversible oxidation processes (at 1.6 and $1.9 \mathrm{~V}$ ), and the third pulse $(1.0 \mathrm{~V})$ was used for 
regeneration of the surface of the boron-doped diamond electrode.

Diazepam (DZP) (7-chloro-1,3-dihydro-1-methyl-5phenyl-2H-1,4-benzodiapin-2-one) belongs to the group of 1,4-benzodiazepines. It is one of the most prescribed 1,4benzodiazepines for a number of conditions such as anxiety, insomnia, epilepsy, and muscular spasms [10]. Its low price and availability on the black market increase the risk of its abuse. Since it is highly liposolubile, it distributes rapidly inside tissues and has the high absorption rate. The absorption rate is increased when it is mixed with alcohol which enhances its sedative effect [11]. That is why diazepam is well known as "date rape" drug, and it is classified as a drug-facilitated crimes (DFC) drug [12]. A fast and simple system for diazepam determination would be of great importance for forensic science and resolving criminal activities which are related with benzodiazepine drug abuse [13].

Determination of benzodiazepines is well documented in the literature, and various spectrophotometric [14] and electrochemical detectors [15-20] were employed. Mass spectrometers were also applied to benzodiazepine determination [21]; their wide linear ranges and low detection limits are advantageous but are still expensive compared to simple flow injection systems.

Although there are many references describing determination of benzodiazepine by electrochemical detectors, there is no paper of DPA application on diazepam determination.

Electrochemical determination of diazepam is based on reduction of 4,5-azomethine group. This simple reduction yielding dihydro specie is used for quantification of diazepam [22]. Applying more negative potentials increases interferences from oxygen, hydrogen ions, and other metal ions present in the sample [23]. Due to high background currents, sensitive determination is almost impossible. Concentration of hydrogen and metal ions is a matter of optimization process and can be controlled. However, the presence of oxygen is more problematic and can be decreased either by removing with nitrogen or by applying modifications of electrode surfaces. Often purging of nitrogen or argon prior the analyses for a few minutes or even overnight is usually enough to remove dissolved oxygen from working solutions [23]. When flow injection systems are applied, another problem arises: the choice of tubing material. Usually, standard Teflon tubings should be avoided due to absorption of oxygen through the polymer. Other polymer materials are more or less chemically inert and also affect the price of the flow system or even using glass or metallic materials but they are too rigid for handling the simple flow system. Lozano-Chaves [15] applied modified carbon-paste electrodes as sensors for the determination of diazepam and its metabolites temazepam and oxazepam in biological fluids. As a modifier, they used $5 \%$ bentonite and $5 \%$ zeolite. Bentonite-modified electrodes showed better sensitivities. Diazepam was determined at $\mathrm{pH} 10$ in Britton-Robinson buffer, with the concentration range of $0.025-3.0 \mathrm{mg} / \mathrm{dm}^{3}$ and the detection limit of $0.021 \mathrm{mg} / \mathrm{dm}^{3}$; all experiments were performed under nitrogen atmosphere. Multiwall carbon nanotube-ionic liquid modified paste electrode was used for diazepam determination in real samples [24]. Analytical parameters for diazepam determination were linearity in the range of $0.02-0.76 \mathrm{mg} / \mathrm{dm}^{3}$ and the detection limit of $4.1 \mu \mathrm{g} / \mathrm{dm}^{3}$. Experiments were performed under nitrogen atmosphere. As mentioned earlier, reduction of 4,5 -azomethine group is often used for quantification of diazepam. Group of authors [20] noticed that there is an oxidation peak in a reverse scan in cyclic voltammetry and they determined the oxidation potential $(+1.0 \mathrm{~V}$ versus $\mathrm{Ag} / \mathrm{AgCl}$ ) for diazepam in drinks on a screen-printed electrode by adsorptive stripping voltammetry. The detector response was linear in the range of $7.1-285 \mathrm{mg} / \mathrm{dm}^{3}$ and a detection limit of $1.8 \mathrm{mg} / \mathrm{dm}^{3}$.

This work presents the development of a flow injection for diazepam determination with differential pulse amperometry and its application in spiked beverage samples without removal of dissolved oxygen.

\section{Materials and Methods}

2.1. Reagents and Chemicals. All reagents used were of analytical grade quality, and all solutions were prepared in degassed and filtered deionised water. Buffer solution of $\mathrm{HCl} / \mathrm{KCl} \mathrm{pH} 1$ was prepared by mixing appropriate volumes of the diluted solution of the hydrochloric acid $\left(0.2 \mathrm{~mol} / \mathrm{dm}^{3}\right.$, Carlo Erba, Val de Reuil, France) and potassium chloride $\left(0.2 \mathrm{~mol} / \mathrm{dm}^{3}\right.$, Betahem, Belgrade, Serbia). Britton-Robinson buffer was prepared by mixing $0.04 \mathrm{~mol} / \mathrm{dm}^{3} \mathrm{CH}_{3} \mathrm{COOH}$ (Carlo Erba, Val de Reuil, France), $0.04 \mathrm{~mol} / \mathrm{dm}^{3} \mathrm{H}_{3} \mathrm{PO}_{4}$ (Carlo Erba, Val de Reuil, France), and $0.04 \mathrm{~mol} / \mathrm{dm}^{3} \mathrm{H}_{3} \mathrm{BO}_{3}$ (Betahem, Belgrade, Serbia), and the $\mathrm{pH}$ value is adjusted with $0.02 \mathrm{~mol} / \mathrm{dm}^{3} \mathrm{NaOH}$ (Betahem, Belgrade, Serbia). The stock solution of diazepam (Hemofarm, Vršac, Serbia) was prepared by dissolving the required mass in methanol to give a concentration of $10 \mathrm{mmol} / \mathrm{dm}^{3}$. Stock solution was maintained under refrigerated conditions in the absence of light, and it was prepared once a week. Working standards were prepared daily by dilution of this solution with appropriate buffers.

2.2. Apparatus. Cyclic voltammetry was used for electrochemical study of diazepam. For the cyclic voltammetry, a CHI $800 \mathrm{C}$ potentiostat was used. A three-electrode system consisted of the glassy carbon working electrode (CH Instruments, USA, model CHI104, $3 \mathrm{~mm}$ in diameter), $\mathrm{Ag} / \mathrm{AgCl}$ reference electrode ( $\mathrm{CH}$ Instruments, USA; CHI111), and platinum wire as auxiliary electrode. $\mathrm{pH}$ measurements were performed using WTW720 pH-meter equipped with SenTix $81 \mathrm{pH}$ electrode. Prior the cyclic voltammetry experiments, all solutions were purged with oxygen free nitrogen for 15 minutes.

Cleaning of glassy carbon electrodes was performed mechanically on a polishing pad using aluminium paste of different grain sizes (1, 0.3, and $0.05 \mu \mathrm{m}$, Buehler, USA). It was washed with distilled water between each paste, and after the finest paste, it was washed with methanol, distilled water, and then air-dried. This process was repeated each day before the start of the recording and in the case if detector response was not reproductive. 
2.3. Flow Injection Analysis System. Peristaltic pump model Mini S 840 (Ismatec, Switzerland) was used. Two-position injection valve model 5020 (Rheodyne, USA) equipped with a sample loop was used. Amperometric flow cell (thin layer, BASi, USA) consists of working, reference, and auxiliary electrodes [25]. The working electrode was glassy carbon electrode (BAS Instruments, model MF-1008, USA) consisting of two circular, dual series electrodes which are embedded in a polymer based on fluorocarbons. The reference $\mathrm{Ag} / \mathrm{AgCl}$ (BAS Instruments, model MF-2021, USA) electrode is filled with $3 \mathrm{~mol} / \mathrm{dm}^{3} \mathrm{NaCl}$ solution, and the auxiliary electrode is made of stainless steel. Teflon gasket was placed between the auxiliary and working electrodes; its thickness regulates the volume of the working solution. Electrochemical measurements were performed on model CHI760b. The CHI software was used for data acquisition.

2.4. Electrochemical Procedure. Each DPA cycle applied to the working electrode consisted of three steps: first step, cleaning potential of $+0.7 \mathrm{~V}$ for $50 \mathrm{~ms}$, second $-0.75 \mathrm{~V}$ for $50 \mathrm{~ms}$ (first potential pulse), and then $-0.95 \mathrm{~V}$ for $50 \mathrm{~ms}$ (second potential pulse). The analytical signal was calculated as the difference between the average signal at last $25 \mathrm{~ms}$ of the second and the first potential pulse. DPA measurements were performed on CHI760b potentiostat. For this set of experiments, there was no need to expel the oxygen from solutions.

\section{Results and Discussion}

3.1. Cyclic Voltammetry of Diazepam and pH Effect. Cyclic voltammograms of a $0.5 \mathrm{~mol} / \mathrm{dm}^{3}$ diazepam in $\mathrm{HCl} / \mathrm{KCl}$ buffer ( $\mathrm{pH}$ 1) were recorded in the potential range of -0.2 to $-0.9 \mathrm{~V}$. Voltammograms were recorded for different scan rates from 20 to $150 \mathrm{mV} \mathrm{s}^{-1}$. In the negative scan, one reduction peak can be observed at around $-0.76 \mathrm{~V}$ (Figure 1). The value of the peak potential became more cathodic with increasing scan rate and varied linearly with square root of scan rate, indicating irreversibility of the reduction and diffusion-controlled process on the electrode surface.

The effect of $\mathrm{pH}$ on reduction of diazepam was investigated when $100 \mu \mathrm{mol} / \mathrm{dm}^{3}$ diazepam was recorded in $\mathrm{HCl} / \mathrm{KCl}$ buffer ( $\mathrm{pH}$ 1) and Britton-Robinson buffer of different $\mathrm{pH}$ (3-8) values in the potential range -0.2 to $-1.2 \mathrm{~V}$. With increase of $\mathrm{pH}$, the cathodic peak shifts to more negative values indicating the dependence of the reduction potential on the $\mathrm{pH}$ value of the medium (Figure 2). As the media becomes less acidic, the FIA signal becomes less stable and reproducible. Hence, the further experiments were performed in $\mathrm{pH} 1$ solutions.

The cathodic peak is a result of a two-electron change, and the reduced product can be characterised as 4,5-dihydrodiazepam (Reaction (1)), as reported elsewhere [22, 26]:

$$
\mathrm{R}-(\mathrm{H}) \mathrm{C}=\mathrm{N}-\mathrm{R}^{\prime}+2 \mathrm{e}^{-}+2 \mathrm{H}^{+} \rightarrow \mathrm{R}-\mathrm{C}(\mathrm{H})_{2}-\mathrm{N}(\mathrm{H})-\mathrm{R}^{\prime}
$$

3.2. Optimization of Flow Injection Parameters. The following parameters were investigated for the sensitivity of the thin-layer flow cell: the volume of the sample loop and the

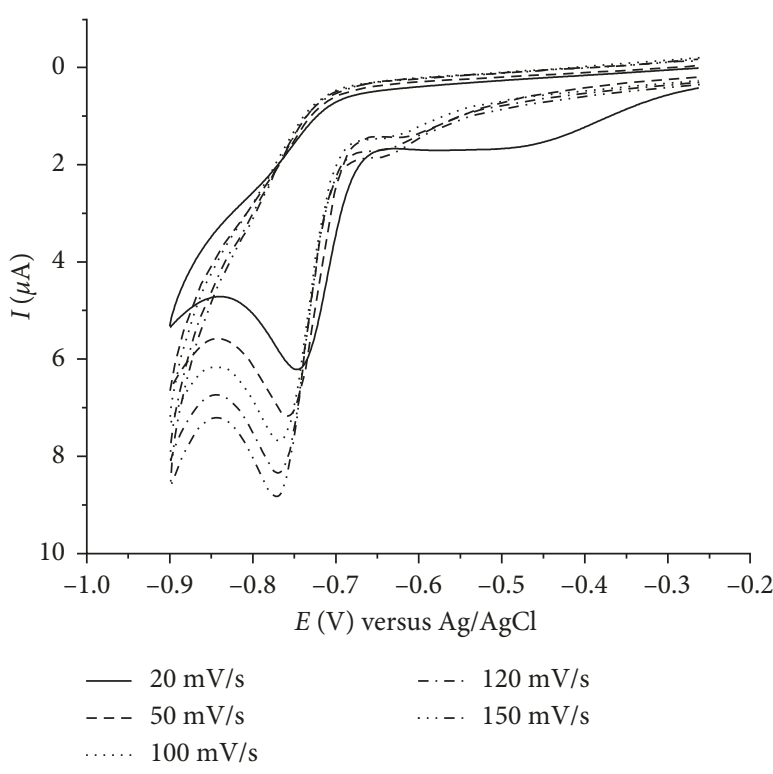

Figure 1: Cyclic voltammograms of $0.5 \mathrm{~mol} / \mathrm{dm}^{3}$ diazepam on glassy carbon electrode as a function of a scan rate $\left(20-150 \mathrm{mV} \mathrm{s}^{-1}\right)$.

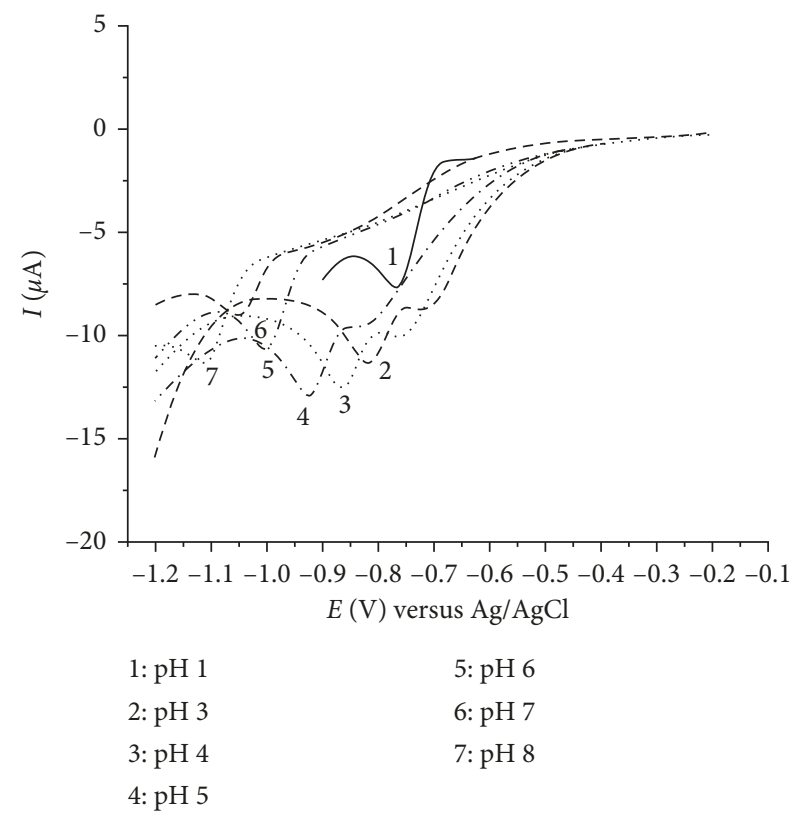

Figure 2: Cyclic voltammograms of $100 \mu \mathrm{mol} / \mathrm{dm}^{3}$ diazepam as function of $\mathrm{pH}$ in $\mathrm{HCl} / \mathrm{KCl}$ buffer $(\mathrm{pH} 1)$ and Britton-Robinson buffer (pH 3-8) at $100 \mathrm{mV} \mathrm{s}^{-1}$ scan rate.

gasket thickness. The optimal conditions in FIA system were investigated with $100 \mu \mathrm{mol} / \mathrm{dm}^{3}$ diazepam solution. Sample loops of $0.050,0.075$, and $0.120 \mathrm{~cm}^{3}$ were tested. The detector response was the most sensitive with $0.050 \mathrm{~cm}^{3}$ of the injected sample. The gasket determines the working volume of the flow cell. All four commercially available gaskets from BASi were tested $(13,51,127$, and $381 \mu \mathrm{m}$ thickness). For this type of flow cell, the best sensitivity was obtained for $51 \mu \mathrm{m}$ thick gasket, which was already confirmed in our previous work [25]. 
3.3. Optimization of Differential Pulse Amperometry. The potentials used for the two DPA pulses were chosen according to the results obtained by cyclic voltammetry. Hence, the DPA pulses should be a little lower and a little higher than the peak potential of diazepam reduction. We investigated the following values of potential pulses, $E_{\text {clean }}$ 0 to $+1 \mathrm{~V}, E_{1}-0.6$ to $-0.75 \mathrm{~V}$, and $E_{2}-0.8$ to $-0.95 \mathrm{~V}$; each potential was held for $50 \mathrm{~ms}$, and the current was collected at last $25 \mathrm{~ms}$ for $E_{2}$ and $E_{1}$. All experiments were performed with $0.1 \mathrm{mmol} / \mathrm{dm}^{3}$ diazepam solution in $\mathrm{HCl} / \mathrm{KCl}$ buffer $\mathrm{pH}$ 1. The $0.7 \mathrm{~V}$ was applied for cleaning potential due to the signal shape and the system reproducibility. The sensitivity of the detector for different values of $E_{1}$ and $E_{2}$ is presented in Table 1, and it shows that the best response was obtained for $E_{1}=-0.75 \mathrm{~V}$ and $E_{2}=-0.95 \mathrm{~V}$. Figure 3 presents the DPA waveform applied for diazepam.

Under these conditions, there was no need for purging the solutions prior the experiments or working in the inert atmosphere.

3.4. Analytical Parameters. The calibration curve obtained from the DPA peak current for diazepam reduction at different diazepam concentration shows linear behaviour between 20 and $250 \mu \mathrm{mol} / \mathrm{dm}^{3}$ with the regression equation $\Delta I(\mu \mathrm{A})=0.063 c(\mu \mathrm{M})+0.430 \quad$ (Figure 4$)$. The presented calibration curve is the average obtained from the three curves recorded for the same set of standards; error bars in each point of the curve are standard deviations. The detection limit was calculated to be $13.4 \mu \mathrm{mol} / \mathrm{dm}^{3}$, but measured as $3 \mathrm{~s} / \mathrm{m}$, where $s$ is the standard deviation and $m$ is the slope, and the limit of quantification was calculated to be $44.8 \mu \mathrm{mol} / \mathrm{dm}^{3}$. Obtained limit of the detection is not comparable to LODs obtained by hyphenated techniques (chromatography/mass spectrometry) which often require complicated sample preparation [13, 27-30]. Electrochemical detection is seldom described for determination of diazepam in beverage samples. Honeychurch et al. [20] applied adsorptive stripping voltammetry with medium exchange limit, and the limit of detection was $1.8 \mu \mathrm{g} \mathrm{cm}^{-3}$.

The absolute limit of detection for the sample loop volume of $0.050 \mathrm{~cm}^{3}$ was $0.19 \mu \mathrm{g}$ of diazepam. Reproducibility of the system was checked by six consecutive injections of $100 \mu \mathrm{mol} / \mathrm{dm}^{3} \mathrm{DZP}$ on the same day for investigation of intraday precision (insert picture on Figure 4), and the relative standard deviation for intraday precision was $1.53 \%$. Interday precision was obtained by recording peak current of $100 \mu \mathrm{mol} / \mathrm{dm}^{3} \mathrm{DZP}$ during three consecutive days; the results showed decrease of precision, presented by the relative standard deviation of $10.8 \%$ for interday measurements. Since simple flow injection system was used and the signal frequency was dependent on tubing length, only the throughoutput was up to 90 analyses per hour (Table 2).

3.5. Interference Study. Ascorbic acid, lactose, glucose, and citric acid are the common compounds present in the beverage samples. The effect of interferants on diazepam determination was investigated by injecting solutions containing $100 \mu \mathrm{mol} \mathrm{dm}{ }^{-3}$ of each interferant and mixtures
TABle 1: Sensitivities at different $E_{1}$ and $E_{2}$ values for FIA-DPA.

\begin{tabular}{lcc}
\hline$E_{1}(\mathrm{~V})$ & $E_{2}(\mathrm{~V})$ & Slope $\left(\mathrm{nA} \mathrm{dm}^{3} \mathrm{~mol}^{-1}\right)$ \\
\hline-0.6 & -0.8 & 35 \\
-0.65 & -0.8 & 42 \\
-0.7 & -0.8 & 31.3 \\
-0.75 & -0.8 & 14.2 \\
-0.75 & -0.9 & 38.8 \\
-0.75 & -0.95 & 92.7 \\
\hline
\end{tabular}

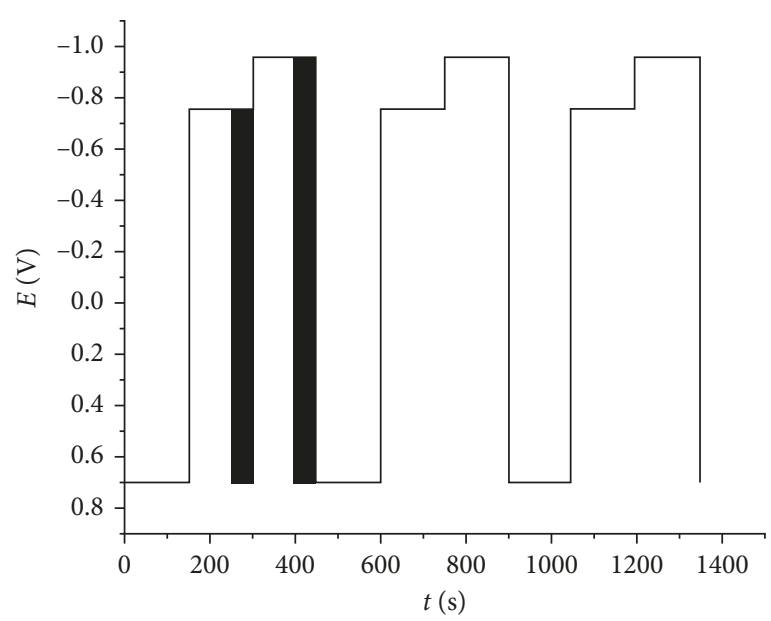

FIGURE 3: Schematic presentation of DPA waveform applied for diazepam determination. The squares are used for current measurement.

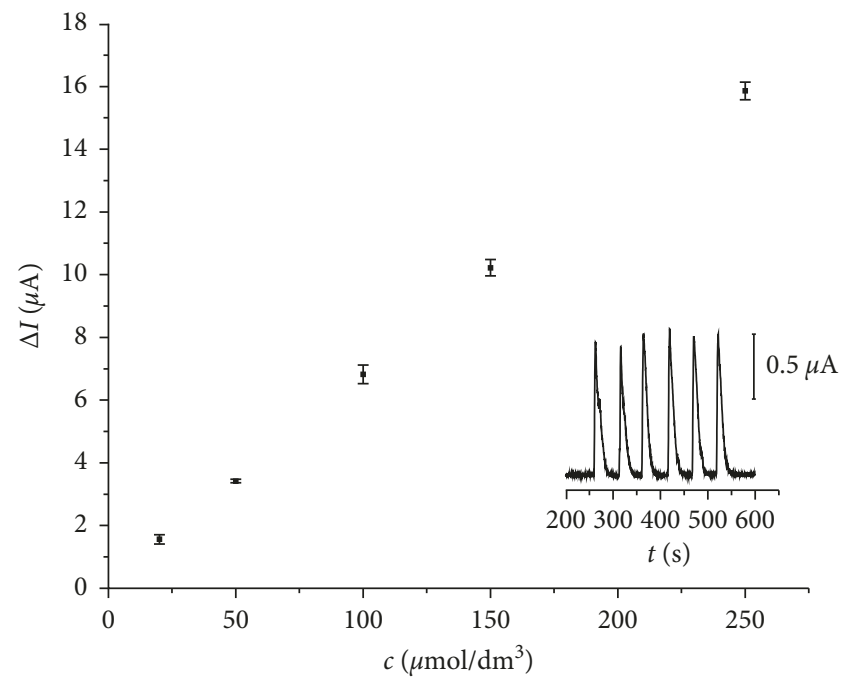

Figure 4: Linear response for FIA-DPA system for $20-250 \mu \mathrm{mol} / \mathrm{dm}^{3}$ diazepam. Inset: six consecutive injections of $100 \mu \mathrm{mol} / \mathrm{dm}^{3}$ of diazepam.

with diazepam of the same concentration. Results showed that interferants decrease diazepam signal by $4-10 \%$ (Table 3 ).

3.6. Determination of Diazepam in Beverage Samples. The purpose of this method was to investigate concentrations relevant for forensic studies. On Serbian market, diazepam 
TABLE 2: Analytical characteristics of the proposed methods.

\begin{tabular}{|c|c|}
\hline Characteristics & FIA-DPA \\
\hline $\mathrm{LR}, \mu \mathrm{mol} \mathrm{dm}{ }^{-3}$ & $20-250$ \\
\hline Sensitivity, $\mathrm{nA} \mathrm{dm}{ }^{3} \mu \mathrm{mol}^{-1}$ & 63 \\
\hline Correlation coefficient, $r$ & 0.997 \\
\hline $\mathrm{LOD}, \mu \mathrm{mol} \mathrm{dm}{ }^{-3}$ & 13.4 \\
\hline Intraday RSD $(n=6)$ & $1.53 \%$ \\
\hline Interday RSD $(n=3)$ & $10.8 \%$ \\
\hline Throughoutput, $1 \mathrm{~h}^{-1}$ & 90 \\
\hline
\end{tabular}

TABLE 3: Results of interference study.

\begin{tabular}{lc}
\hline Interferent & Relative signal decrease (\%) \\
\hline Citric acid & 4 \\
Lactose & 5 \\
Ascorbic acid & 8 \\
Glucose & 10 \\
\hline
\end{tabular}

TABLE 4: Analysis results of the recovery for spiked samples $(n=3)$.

\begin{tabular}{lccc}
\hline Sample & $\begin{array}{c}\text { Spiked } \\
\text { concentration } \\
\left(\mu \mathrm{mol} / \mathrm{dm}^{3}\right)\end{array}$ & $\begin{array}{c}\text { Results }(\text { mean } \pm \text { SD }) \\
\left(\mu \mathrm{mol} / \mathrm{dm}^{3}\right)\end{array}$ & $\begin{array}{c}\text { Recovery } \\
\text { ratio }(\%)\end{array}$ \\
\hline \multirow{3}{*}{ Guarana } & 50 & $52.48 \pm 0.80$ & 104.96 \\
& 100 & $101.25 \pm 1.55$ & 101.25 \\
Beer I & 150 & $152.05 \pm 2.33$ & 101.37 \\
& 50 & $47.51 \pm 0.73$ & 95.02 \\
Beer II & 100 & $94.31 \pm 1.44$ & 94.31 \\
& 150 & $139.48 \pm 2.13$ & 92.99 \\
& 50 & $49.12 \pm 0.75$ & 98.24 \\
& 100 & $96.24 \pm 1.47$ & 96.24 \\
\end{tabular}

tablets containing 2, 5, or $10 \mathrm{mg}$ of active substance are available; when a tablet is dissolved in $200 \mathrm{~cm}^{3}$ of a beverage, obtained concentrations are from $35-175 \mu \mathrm{mol} / \mathrm{dm}^{3}$ of diazepam, which fits in the linear range of the detector.

Beverage samples (Guarana and two beer samples) were purchased at a local store. $12.5 \mathrm{~cm}^{3}$ of a sample was diluted with buffer and appropriate volume of diazepam standard solution, ultrasonicated for 30 minutes, and made up with distilled water to $25.00 \mathrm{~cm}^{3}$. The samples were spiked with $50 \mu \mathrm{mol} / \mathrm{dm}^{3}$ of diazepam. Solutions were injected in triplicate, and the results of recoveries for spiked samples of different concentrations are presented in Table 4.

\section{Conclusions}

Flow injection method with differential pulse amperometry was developed and applied for quantification of diazepam in investigated set of beverage samples. Differential pulse amperometry enables the determinations in the presence of oxygen without surface modification. Under the optimal conditions, the linear range of the system was from 20 to $250 \mu \mathrm{mol} / \mathrm{dm}^{3}$ of diazepam, with the detection limit of $3.83 \mu \mathrm{g} / \mathrm{cm}^{3}$, the intraday precision of $1.53 \%$, and a throughoutput of 90 analyses per hour. The method was applied on diazepam determination in beverage samples; $0.050 \mathrm{~cm}^{3}$ of sample was enough for fast, precise, and sensitive quantification. With the flow rate of $1 \mathrm{~cm}^{3} / \mathrm{min}$, the method is economical, producing small volumes of waste. The simple sample preparation enables injection of samples without extraction or filtration.

\section{Conflicts of Interest}

The authors declare that there are no conflicts of interest regarding the publication of this paper.

\section{Acknowledgments}

This work was done within the framework of the research Project no. 172051 supported by the Ministry of Education, Science and Technological Development of Serbia.

\section{References}

[1] N. R. Stradiotto, H. Yamanaka, and M. V. B. Zanoni, "Electrochemical sensors: a powerful tool in analytical chemistry," Journal of the Brazilian Chemical Society, vol. 14, no. 2, pp. 159-173, 2003.

[2] F. Marcenac and F. Gonon, "Fast in vivo monitoring of dopamine release in the rat brain with differential pulse amperometry," Analytical Chemistry, vol. 57, no. 8, pp. 1778-1779, 1985.

[3] F. J. Heredia-López, J. L. Góngora-Alfaro, F. J. AlvarezCervera, and J. L. Bata-Garćia, "A PC-controlled voltage pulse generator for electroanalytical applications," Review of Scientific Instruments, vol. 68, no. 4, pp. 1879-1885, 1997.

[4] W. Surareungchai, W. Deepunya, and P. Tasakorn, "Quadruple-pulsed amperometric detection for simultaneous flow injection determination of glucose and fructose," Analytica Chimica Acta, vol. 448, no. 1-2, pp. 215-220, 2001.

[5] R. A. Medeiros, B. C. Lourenção, R. C. Rocha-Filho, and O. Fatibello-Filho, "Simple flow injection analysis system for simultaneous determination of phenolic antioxidants with multiple pulse amperometric detection at a boron-doped diamond electrode," Analytical Chemistry, vol. 82, no. 20, pp. 8658-8663, 2010.

[6] W. T. P. Dos Santos, E. G. N. De Almeida, H. E. A. Ferreira, D. T. Gimenes, and E. M. Richter, "Simultaneous flow injection analysis of paracetamol and ascorbic acid with multiple pulse amperometric detection," Electroanalysis, vol. 20, no. 17, pp. 1878-1883, 2008.

[7] S. C. Chaves, P. N. C. Aguiar, L. M. F. C. Torres et al., "Simultaneous determination of caffeine, ibuprofen, and paracetamol by flow-injection analysis with multiple-pulse amperometric detection on boron-doped diamond electrode," Electroanalysis, vol. 27, no. 12, pp. 2785-2791, 2015.

[8] W. T. P. dos Santos, D. T. Gimenes, E. G. N. de Almeida, S. P. Eiras, Y. D. T. Albuquerque, and E. M. Richter, "Simple flow injection amperometric system for simultaneous determination of dipyrone and paracetamol in pharmaceutical formulations," Journal of the Brazilian Chemical Society, vol. 20, no. 7, pp. 1249-1255, 2009.

[9] A. Carlos, V. Lopes Júnior, R. De Cássia et al., “Determination of sildenafil citrate $\left(\right.$ Viagra $\left.^{\circledR}\right)$ in various pharmaceutical formulations by flow injection analysis with multiple pulse amperometric detection," Journal of the Brazilian Chemical Society, vol. 23, no. 10, pp. 1800-1806, 2012. 
[10] J. Riss, J. Cloyd, J. Gates, and S. Collins, "Benzodiazepines in epilepsy: pharmacology and pharmacokinetics," Acta Neurologica Scandinavica, vol. 118, no. 2, pp. 69-86, 2008.

[11] F. Charlson, L. Degenhardt, J. McLaren, W. Hall, and M. Lynskey, "A systematic review of research examining benzodiazepine-related mortality," Pharmacoepidemiology and Drug Safety, vol. 18, no. 2, pp. 93-103, 2009.

[12] D. S. M. Ribeiro, J. A. V. Prior, J. L. M. Santos, and J. L. F. C. Lima, "Automated determination of diazepam in spiked alcoholic beverages associated with drug-facilitated crimes," Analytica Chimica Acta, vol. 668, no. 1, pp. 67-73, 2010.

[13] M. Acikkol, S. Mercan, and S. Karadayi, "Simultaneous determination of benzodiazepines and ketamine from alcoholic and nonalcoholic beverages by GC-MS in drug facilitated crimes," Chromatographia, vol. 70, no. 7-8, pp. 1295-1298, 2009.

[14] A. M. Gil Tejedor, P. Fernández Hernando, and J. S. Durand Alegría, "A rapid fluorimetric screening method for the 1,4benzodiazepines: determination of their metabolite oxazepam in urine," Analytica Chimica Acta, vol. 591, no. 1, pp. 112-115, 2007.

[15] M. E. Lozano-Chaves, J. M. Palacios-Santander, L. M. CubillanaAguilera, I. Naranjo-Rodríguez, and J. L. Hidalgo-Hidalgo-deCisneros, "Modified carbon-paste electrodes as sensors for the determination of 1,4-benzodiazepines: application to the determination of diazepam and oxazepam in biological fluids," Sensors and Actuators B: Chemical, vol. 115, no. 2, pp. 575-583, 2006.

[16] M. M. Correia dos Santos, V. Famila, and M. L. Simões Gonçalves, "Copper-psychoactive drug complexes: a voltammetric approach to complexation by 1,4-benzodiazepines," Analytical Biochemistry, vol. 303, no. 2, pp. 111-119, 2002.

[17] G. B. El-Hefnawey, I. S. El-Hallag, E. M. Ghoneim, and M. M. Ghoneim, "Voltammetric behavior and quantification of the sedative-hypnotic drug chlordiazepoxide in bulk form, pharmaceutical formulation and human serum at a mercury electrode," Journal of Pharmaceutical and Biomedical Analysis, vol. 34, no. 1, pp. 75-86, 2004.

[18] V. K. Gupta, R. Jain, K. Radhapyari, N. Jadon, and S. Agarwal, "Voltammetric techniques for the assay of pharmaceuticals-a review," Analytical Biochemistry, vol. 408, no. 2, pp. 179-196, 2011.

[19] C. G. Amorim, A. N. Araújo, M. C. B. S. M. Montenegro, and V. L. Silva, "Cyclodextrin-based potentiometric sensors for midazolam and diazepam," Journal of Pharmaceutical and Biomedical Analysis, vol. 48, no. 4, pp. 1064-1069, 2008.

[20] K. C. Honeychurch, A. Crew, H. Northall et al., "The redox behaviour of diazepam $\left(\right.$ Valium $\left.^{\circledR}\right)$ using a disposable screenprinted sensor and its determination in drinks using a novel adsorptive stripping voltammetric assay," Talanta, vol. 116, pp. 300-307, 2013.

[21] R. Wang, X. Wang, C. Liang et al., "Direct determination of diazepam and its glucuronide metabolites in human whole blood by $\mu$ Elution solid-phase extraction and liquid chromatography-tandem mass spectrometry," Forensic Science International, vol. 233, no. 1-3, pp. 304-311, 2013.

[22] N. Nagappa, T. Mimani, B. Sheshadri, and S. M. G. Mayanna, "Cyclic voltammetric studies of diazepam using glassy carbon electrode-estimation of diazepam in pharmaceutical samples," Chemical \& Pharmaceutical Bulletin, vol. 46, no. 4, pp. 715-717, 1998.

[23] W. Lund, M. Hannisdal, and T. Greibrokk, "Evaluation of amperometric detectors for high-performance liquid chromatography: analysis of benzodiazepines," Journal of Chromatography A, vol. 173, no. 2, pp. 249-261, 1979.

[24] M. A. Zare, M. S. Tehrani, S. W. Husain, and P. A. Azar, "Multiwall carbon nanotube-ionic liquid modified paste electrode as an efficient sensor for the determination of diazepam and oxazepam in real samples," Electroanalysis, vol. 26, no. 12, pp. 2599-2606, 2014.

[25] A. Lolić, S. Nikolić, and P. Polić, "Optimization and application of the gas-diffusion flow injection method for the determination of chloride," Journal of the Serbian Chemical Society, vol. 66, no. 9, pp. 637-646, 2001.

[26] L. Thomas, J. L. Vilchez, G. Crovetto, and J. Thomas, "Electrochemical reduction of diazepam," Journal of Chemical Sciences, vol. 98, no. 3, pp. 221-228, 1987.

[27] M. Gros, S. Rodríguez-Mozaz, and D. Barceló, "Fast and comprehensive multi-residue analysis of a broad range of human and veterinary pharmaceuticals and some of their metabolites in surface and treated waters by ultra-highperformance liquid chromatography coupled to quadrupolelinear ion trap tandem mass spectrometry," Journal of Chromatography A, vol. 1248, pp. 104-121, 2012.

[28] K. Soltaninejad, M. Karimi, A. Nateghi, and B. Daraei, "Simultaneous determination of six benzodiazepines in spiked soft drinks by high performance liquid chromatography with ultra violet detection (HPLC-UV)," Iranian Journal of Pharmaceutical Research, vol. 15, no. 2, pp. 457-463, 2016.

[29] G. Famigliani, V. Termopoli, P. Palma, and A. Cappielo, "Liquid chromatography-electron ionization tandem mass spectrometry with the Direct-EI interface in the fast determination of diazepam and flunitrazepam in alcoholic beverages," Electrophoresis, vol. 37, no. 7-8, pp. 1048-1054, 2016.

[30] L. Gautam, S. Sharratt, and M. Cole, "Drug facilitated sexual assault: detection and stability of benzodiazepines in spiked drinks using gas chromatography-mass spectrometry," PLoS One, vol. 9, no. 2, article e89031, 2014. 

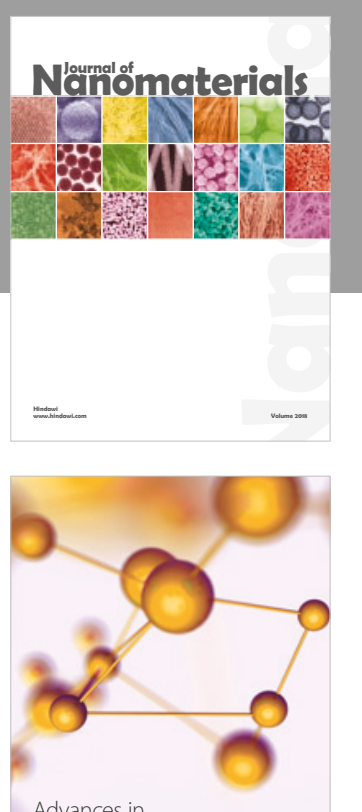

Physical Chemistry
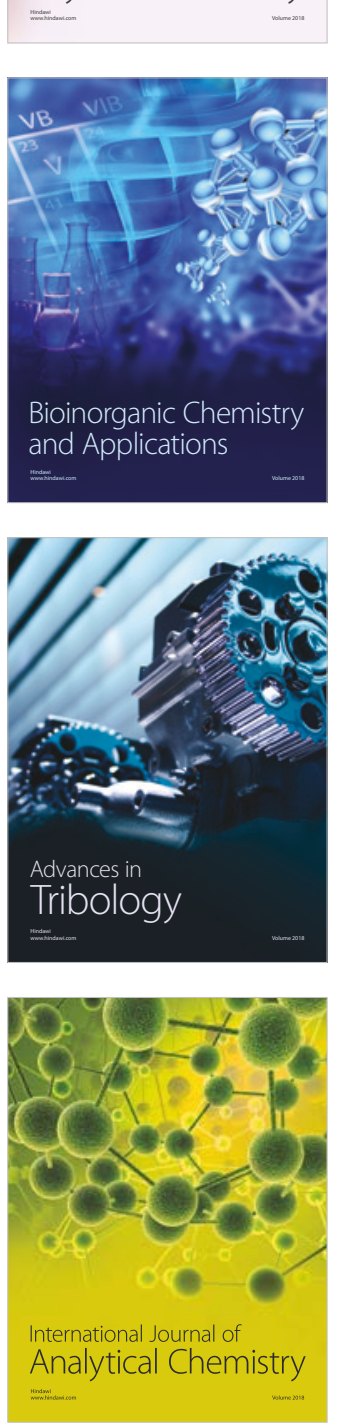

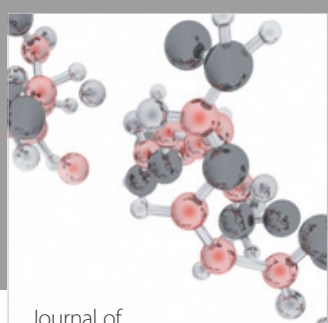

Analytical Methods

in Chemistry

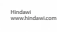

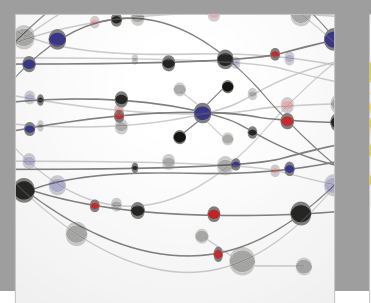

The Scientific World Journal

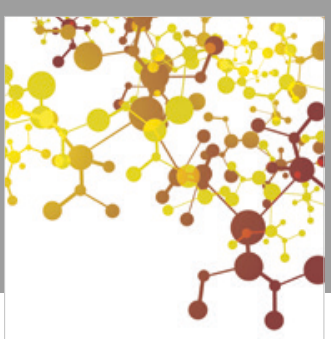

Journal of

Applied Chemistry
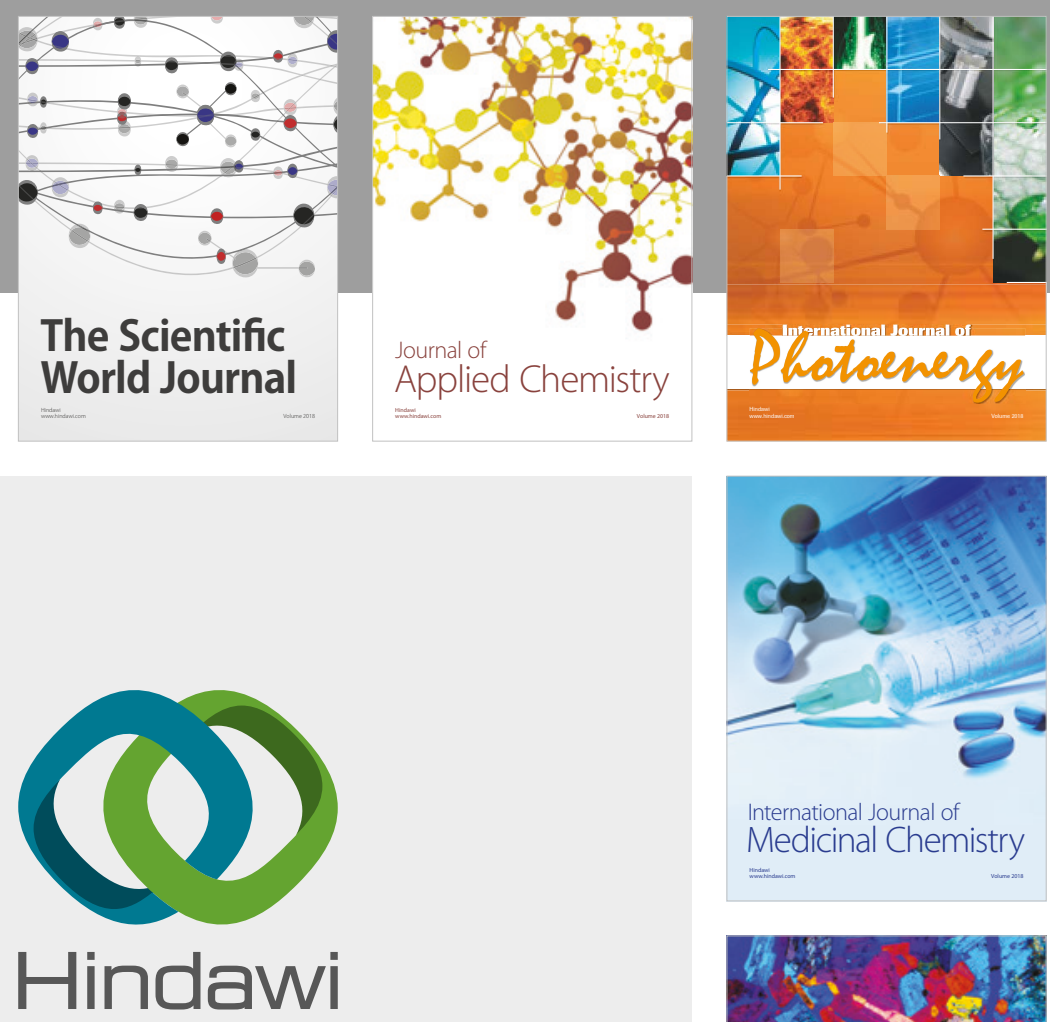

Submit your manuscripts at

www.hindawi.com
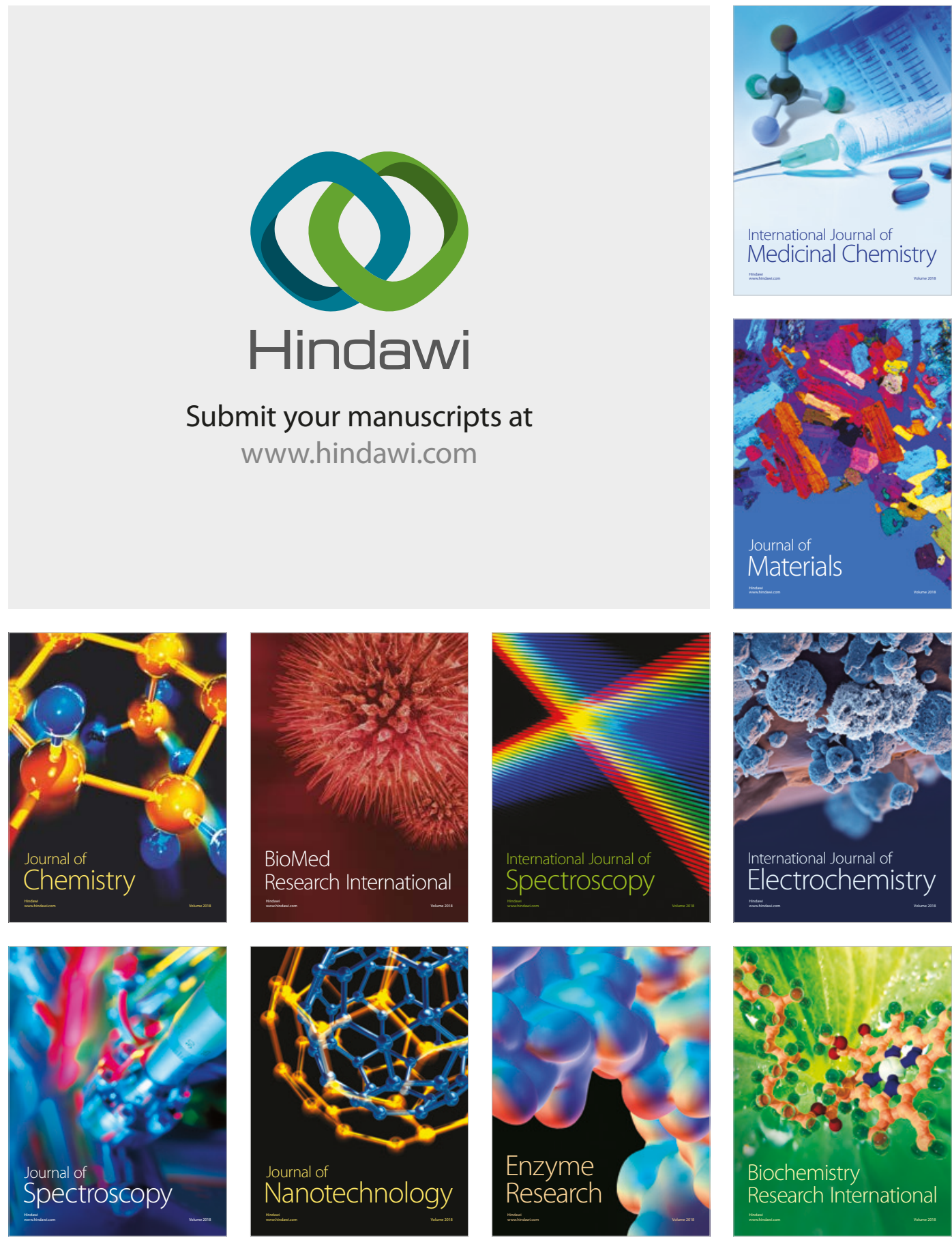
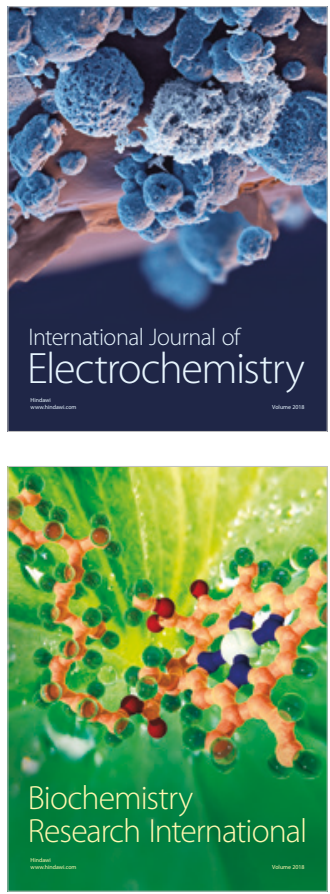